National Geographic Guide has good illustrations which cover a greater variety of plumages (i.e. subspecies and varieties), adequate text, adequate maps and good organization. The Audubon Master Guide uses primarily photos for illustrations and many of these are not adequate, the text is excellent, maps good and organization poor.

Which would I take in the field with me? Unfortunately all four and a packhorse! I do not trust any one guide because of inconsistencies between them. If I had to choose one, probably the National Geographic Guide, then Robbins, followed by the Master Guide (in spite of its cumbersome size) and unfortunately Peterson last. I say unfortunately because I prefer the Peterson illustrations and guide organization but do not like getting caught having a guide which may not illustrate what I may see. - Wayne C. Harris, Box 414, Raymore, Saskatchewan. SOA 3J0

\section{FIELD GUIDE PREFERENCE}

The following is a ranking of three recently released field guides in order of my preference.

My favourite is the National Geographic Society's. This book contains North American species plus an impressive number of stragglers. The degree of coverage of subspecies is an outstanding feature. The thirteen artists portray generally accurate, detailed and richly colored illustrations, however the variance in style is sometimes distracting. Most plates contain examples of both sexes seasonal plumages, immatures, readily identifiable subspecies and flight views. Group plates provide direct comparisons with similar species. The flying ducks are my favourite. The side view allows one to see the birds as they appear "flying by", with the underside and the top of the wing shown in one figure. (This is in contract to the Golden Guide's gliding or banking bird, requiring two illustrations.) A major weakness is the lack of diagnostic arrows as quick visual reference for identification. Maps show state and provincial boundaries and the text, though brief contains much information.

My second choice is the revised, expanded Golden Guide (Robbins, et al), now containing illustrations and written references for Alaskan and Florida stragglers in addition to North American residents including many subspecies. Some of the new plates are disappointing (i.e. the Alaskan peeps are not clearly illustrated or properly coloured). Several revised pages now seem crowded. Some stragglers are only illustrated in male nuptial plumage. The original plates are excellent but again this book does not feature diagnostic arrows. There are more voice sonograms, excellent range maps with migration routes and brief commentaries.

The Audubon Society's three volume set has a fundamental problem. Too many of the photos do not show critical diagnostic features although this guide does feature margin miniatures with diagnostic arrows. Fewer stragglers and subspecies are included. There are very few flight views. The small range maps do not show boundaries. Species information is provided by various regional and national experts. The text is better than the others, but the book is an expensive, limited reference source, with several reviews containing the same criticisms. - Bob Luterbach, 3040 18th Avenue, Regina, Saskatchewan. S4T 1W6 